\title{
Divergência genética em germoplasma de aveias silvestres com base em caracteres multicategóricos e quantitativos
}

\author{
Simone Meredith Scheffer-Basso ${ }^{1}$, Juliana Orsato ${ }^{2}$, Glaci Venturini Moro², \\ Ana Christina Sagebin Albuquerque
}

\begin{abstract}
RESUMO
As aveias silvestres são importantes fontes de genes para programas de melhoramento e sua caracterização é fundamental para a efetiva conservação e uso. Por isso, o objetivo deste estudo foi avaliar a divergência genética em uma coleção de 71 subamostras de aveias silvestres, do Banco de Germoplasma da Embrapa Trigo, com base em caracteres multicategóricos e quantitativos. Procederam-se às análises de variância, para os caracteres quantitativos, e multivariada, para ambos os tipos de caracteres. Os métodos de agrupamento UPGMA, a partir da distância euclidiana média (caracteres multicategóricos), e de ligação completa, com base na distância de Mahalanobis (caracteres quantitativos), foram os mais adequados para ilustrar a relação entre as subamostras. A pilosidade da base dos grãos foi o caractere com maior contribuição relativa para divergência genética $(32,16 \%)$ e a menor contribuição foi da pilosidade do nó superior $(0,081 \%)$. As subamostras divergiram quanto a vinte caracteres: pilosidade da bainha da folha inferior, bordas da lâmina imediatamente abaixo da folha bandeira, nó superior, face externa do lema e base do grão; posição da folha bandeira e das ramificações na panícula; frequência de plantas com folha bandeira recurvada; intensidade da pilosidade do nó superior e da cerosidade do lema; orientação das ramificações na panícula; comprimento dos pelos basais do grão, ráquila, panícula, glumas e planta; cor do lema, tipo de arista, número de grãos por espigueta e ciclo. O germoplasma apresenta elevada variabilidade genética e genes de interesse para o melhoramento de aveias.
\end{abstract}

Palavras-chave: Avena spp., análise multivariada, descritores, variáveis multicategóricas.

\section{ABSTRACT}

\section{Genetic divergence in wild oat germplasm based on multicategoric and quantitative traits}

The wild oats are an important source of genes for breeding programs and their characterization is essential for effective conservation and use. This study aimed to evaluate the genetic divergence among 71 subsamples of wild oats (A. abyssinica, A. barbata, A. brevis, A. fatua, A. longiglumis, A. sterilis, A. vaviloviana and A. wiestii) based on 25 multicategoric and quantitative traits. Analyzes of variance, for quantitative traits, and multivariate, for both types of characters, were carried out. The UPGMA clustering, based on average Euclidean distance (multicategoric characters), and the complete linkage, based on Mahalanobis distance (quantitative traits), were the most appropriate methods to illustrate the relationship among the subsamples. The hairiness of the base of the grain was the trait with the greatest relative contribution to genetic divergence $(32.16 \%)$, whereas the smallest contribution was the hairiness of the uppermost node $(0.081 \%)$. The subsamples differed for twenty traits: hairiness of sheath of lower leaf, margin of leaf below flag leaf, uppermost node, external surface of lemma and base of the grain; position of the flag leaf and panicle

Recebido para publicação em 15/04/2011 e aprovado em 12/09/2012.

'Engenheira-Agrônoma, Doutora. Instituto de Ciências Biológicas, Universidade de Passo Fundo, Campus I, Bairro São José, BR 285, 99052-900, Passo Fundo, Rio Grande do Sul, Brasil. sbasso@upf.br (autora para correspondência).

${ }^{2}$ Graduandas em Ciências Biológicas. Universidade de Passo Fundo, Campus I, Bairro São José, BR 285, 99052-900, Passo Fundo, Rio Grande do Sul, Brasil. Bolsista Pibic CNPq. julianaorsato@yahoo.com.br, glaciventurini@gmail.com

${ }^{3}$ Engenheira-Agrônoma, Mestre. Embrapa Trigo, Rodovia BR 285, Km 294, Caixa Postal 451, 99001-970, Passo Fundo, Rio Grande do Sul, Brasil. ana@cnpt.embrapa.br 
branches; frequency of plants with flag leaf curved; intensity of hairiness of the uppermost node and glaucosity of lemma; orientation of branches in the panicle; length of the basal hairs of the grain, rachilla, panicle, glumes and plant; color of lemma, awn type, number of grains per spikelet, and cycle. The germplasm has high genetic variability and genes of interest for the improvement of oats.

Key words: Avena ssp., descriptors, multicategoric variables, multivariate analysis.

\section{INTRODUÇÃO}

Entre os principais cereais cultivados no Brasil, espécies de Avena L. destacaram-se nas últimas décadas, com a liberação de dezenas de cultivares de aveia-branca (Avena sativa L.) e aveia-preta (A. strigosa Schreb.). Os programas de melhoramento genético de aveia-branca têm sido eficientes na obtenção de cultivares mais produtivos, com melhor qualidade de grãos e com características agronômicas superiores, mas o patamar máximo para melhoramento dessa espécie ainda não foi atingido, o que possibilita a obtenção de ganhos genéticos (Barbosa Neto et al., 2000). O avanço nos programas de melhoramento genético de aveias depende da variabilidade genética presente nos bancos de germoplasma, sendo necessária a adequada caracterização e divulgação dessa variabilidade para que ela possa ser acessada.

As aveias silvestres são consideradas invasoras e raramente são cultivadas, mas podem ser utilizadas como fonte de genes para o melhoramento genético de aveias domesticadas. As principais espécies silvestres do gênero são as diploides (Avena brevis Roth., A. longiglumis Dur. e A. wiestii Steudel), as tetraploides (A. abyssinica Hochst., A. barbata Pott ex Link. e A. vaviloviana (Malz.) Mordv.) e as hexaploides (A. fatua L. e A. sterilis L.) (Leggett, 1992). A. barbata é uma espécie adaptada a diferentes condições ambientais, incluindo baixa disponibilidade de água, elevadas altitudes e altas temperaturas e, por sua ampla adaptação, apresenta-se como um pool gênico de interesse para programas de melhoramento de aveia (Somersalo et al., 1998). Segundo Swarbreck et al. (2011), essa espécie tem sido objeto de estudos ecológicos, com a finalidade de entender o efeito das mudanças climáticas nos ecossistemas pastoris e a base genética para adaptação a variações ambientais, constituindo importante fonte de alelos para uso em espécies afins. Aung et al. (1977) transferiram, com sucesso, a resistência dessa espécie ao míldio (Erysiphe graminis f. sp. avenae) para aveia-branca.

Dentre as espécies silvestres, existe especial interesse nas hexaploides, pois elas têm o mesmo número cromossômico da aveia-branca, não havendo barreira de ploidia para introgressão de seus caracteres no germoplasma cultivado (Matiello et al., 1999). Contudo, existem vários relatos da possibilidade de introgressão de germoplasma silvestre, usando, também, espécies com diferentes níveis de ploidia. Tavares et al. (1993) relataram a obtenção de anfipoliploides sintéticos de $A$. abyssinica $\mathrm{x}$ A. strigosa Shreb., que foram utilizados para transferência de genes do grupo strigosa para o grupo sativa. Ahokas \& Manninem (2000) obtiveram uma planta hexaploide fértil, após várias gerações de seleção, mediante um híbrido decaploide produzido com colchicina, A. abyssina x A. sativa, que mostrou fertilidade estável e precocidade.

Estratégias para a conservação ex situ de aveias são apresentadas por Germeir (2008), para o qual a caracterização das subamostras, seguida da divulgação dos resultados, é uma das mais importantes e trabalhosas ações que necessitam ser desenvolvidas nos bancos de germoplasma. Somente assim, curadores, melhoristas e taxonomistas terão acesso à variabilidade genética presente nas coleções.

No Brasil, o Ministério da Agricultura, Pecuária e Abastecimento (Brasil, 2002) regulamenta o processo de caracterização de cultivares de aveia com base nos descritores do IBPGR (1985). Os descritores são atributos, características ou caracteres mensuráveis, que são observados em uma subamostra do banco de germoplasma, para os quais são alocados códigos numéricos (Biodiversity International, 2007), caracterizando-se, estatisticamente, como variáveis multicategóricas.

$\mathrm{Na}$ exploração de dados multicategóricos, a análise multivariada tem sido largamente aplicada, permitindo verificar a dissimilaridade no germoplasma, representar a relação entre as subamostras, por dendrogramas ou gráficos de dispersão, e identificar os caracteres com maior contribuição para divergência genética, dentre outras aplicações. Quando é possível ordenar esse tipo de dados, estabelecendo-se uma escala, é possível analisá-los como variáveis quantitativas discretas (Sneath \& Sokal, 1973). No entanto, em muitos casos, os valores de certas variáveis multicategóricas não podem ser ordenados, remetendo à análise mediante índices de similaridade, cujo valor expressa o nível, ou a percentagem, de coincidência de valores (Cruz, 2006). 
O objetivo deste trabalho foi avaliar a divergência genética em uma coleção de 71 subamostras de aveias silvestres, do Banco de Germoplasma da Embrapa Trigo, com base em caracteres multicategóricos e quantitativos.

\section{MATERIAL E MÉTODOS}

O trabalho foi desenvolvido em Passo Fundo, região fisiográfica do Planalto Médio do Rio Grande do Sul, a $28^{\circ} 15^{\prime} \mathrm{S}$ e $52^{\circ} 24^{\prime} \mathrm{W}$ e $687 \mathrm{~m}$ de altitude média, com clima fundamental úmido (f) e variedade subtropical (Cfa) (Kuinchtner \& Burial, 2001). Foram avaliadas 71 subamostras de aveias silvestres de diferentes procedências (Tabela 1). As plantas foram cultivadas em telado, em delineamento inteiramente casualizado, com duas repetições. As unidades experimentais foram constituídas de vasos de plástico contendo $5 \mathrm{~kg}$ de solo, no qual foram cultivadas três plantas. A irrigação foi realizada automaticamente, por gotejamento.

As subamostras foram caracterizadas de acordo com os descritores para aveia para 25 caracteres morfoagronômicos, multicategóricos (22) e quantitativos (3). A metodologia seguiu as instruções para execução dos ensaios de distinguibilidade, homogeneidade e estabilidade de cultivares de aveia (Brasil, 2002). As avaliações ocorreram em estádios fenológicos específicos (Zadoks et al., 1974), com base em escala de códigos sequenciais e não sequenciais, de acordo com avaliações quantitativas ou visuais.
Os caracteres multicategóricos foram os seguintes: 1) pilosidade da bainha da folha inferior; 2) pilosidade das bordas da lâmina imediatamente abaixo da folha bandeira; 3) posição da folha bandeira; 4) frequência de plantas com folha bandeira recurvada; 5) pilosidade do nó superior; 6) intensidade da pilosidade do nó superior; 7) posição das ramificações na panícula; 8) orientação das ramificações na panícula; 9) posição das espiguetas; 10) forma das glumas; 11) pilosidade das glumas; 12) cerosidade do lema; 13) intensidade da cerosidade do lema; 14) pilosidade na face externa do lema; 15) presença de casca no grão; 16) pilosidade na base do grão; 17) comprimento dos pelos basais do grão; 18) comprimento da ráquila; 19) cor do lema; 20) tipo de arista; 21) número de grãos por espigueta; 22) ciclo (número de dias entre a emergência das plantas até a emergência das panículas). Para o germoplasma avaliado, as subamostras foram classificadas quanto ao ciclo, como: muito precoce $=73$ dias; precoce $=79$ dias $;$ médio $=94$ dias; tardio $=115$ dias; muito tardio $=121$ dias. Os caracteres quantitativos foram: 1 ) comprimento da panícula (curto = até $10 \mathrm{~cm}$; médio = entre 11 e $15 \mathrm{~cm}$; longo $=\geq 16 \mathrm{~cm}$ ); 2) comprimento das glumas (curto $=9$ a $16 \mathrm{~mm} ;$ médio $=17$ a $23 \mathrm{~mm} ;$ longo $=24$ a $30 \mathrm{~mm}$ ); 3) comprimento da planta, da base do colmo ao ápice da panícula (muito curto $=\leq 70 \mathrm{~cm}$; curto $=71$ a 90 $\mathrm{cm}$; médio = 91 a $110 \mathrm{~cm}$; longo = 111 a $129 \mathrm{~cm}$; muito longo $=\geq 130 \mathrm{~cm})$.

Tabela 1. Identificação e procedência das subamostras de espécies de aveias silvestres (Avena spp.) do Banco Ativo de Germoplasma da Embrapa Trigo

\begin{tabular}{|c|c|c|}
\hline Espécie & Procedência & Subamostras (sigla e número) \\
\hline \multirow{5}{*}{ A. abyssinica } & Etiópia & $\begin{array}{l}\text { CAV: } 2861 ; 2865 ; 2865 ; 3105 ; 3122 ; 3125 ; 3128 ; 3130 ; 3132 ; 3134 ; \\
\quad \text { 3135; } 3139 ; 3144 ; 3161 ; 3233 ; 3238 ; 3241 \text { e; } 3244 ; \text { CD } 7845 ; \\
\text { CLAV 2109; IPFA: 99003; 99014; 99015; 99016; 99017; 99018; 99019; } \\
\text { 99034; } 99037 \text { e; 99038; K5104; PI: 234842,32 e; } 258539,5970\end{array}$ \\
\hline & Eritréia & CAV: $2939 ; 2964 \mathrm{e} ; 3076$ \\
\hline & Inglaterra & Long Fellow (WIR 2566) \\
\hline & Rússia & CD 7844 e; IPFA 99020 \\
\hline & Desconhecida & IPFA 99032 \\
\hline \multirow[b]{2}{*}{ A. barbata } & Algéria & CAV 0542 \\
\hline & Israel & D: 106; 116; 119; 120 e; 125 \\
\hline \multirow[b]{2}{*}{ A. brevis } & Brasil & CLAV 3436; IPFA 99002 \\
\hline & Portugal & IPFA: 99012 e 99013; Túrgida; WIR: 5226/5 e; 5229 \\
\hline A. fatua & Brasil & BDZA 461 \\
\hline \multirow{4}{*}{ A. longiglumis } & Algéria & CW 53 \\
\hline & Portugal & KM 16256 \\
\hline & Israel & CLAV: 8342 e; 8341 e; WAHL \# 7 \\
\hline & Iraque & CAV 1008 \\
\hline \multirow[b]{2}{*}{ A. sterilis } & Quênia & CAV 3293 \\
\hline & Turquia & CAV: 1878 e; 3361 \\
\hline A. vaviloviana & Etiópia & CAV: 2879; 2891; 2907; 2921; 3258 e; 3309; WIR 779 \\
\hline A.wiestii & Canadá & CD8024 \\
\hline
\end{tabular}

Rev. Ceres, Viçosa, v. 59, n.5, p. 654-667, set/out, 2012 
A partir dos dados originais das variáveis multicategóricas foi obtida a moda para cada subamostra (Sudré et al., 2006), mas, para a análise multivariada, essas variáveis foram caracterizadas como quantitativas discretas ordenadas (Sneath \& Sokal, 1973). A análise da dissimilaridade entre as subamostras foi realizada mediante a obtenção da matriz de distância euclidiana média (D) e cálculo do índice de dissimilaridade (IS) entre os pares, dado pela expressão $\mathrm{CP} /(\mathrm{CP}+\mathrm{D})$, em que $\mathrm{CP}$ indica a concordância de valores e D = discordância de valores (Cruz, 2006), sendo que a unidade indica total concordância de valores. Os comprimentos de planta, panícula e glumas foram avaliados como variáveis quantitativas, sendo realizada a análise de variância e comparação de médias pelo teste de Scott-Knott, a 5\% de probabilidade. Posteriormente, foi gerada a matriz de distância de Mahalanobis $\left(\mathrm{D}^{2}\right)$, uma vez que, para esse procedimento, é necessário informar a matriz de variâncias e covariâncias residuais (Cruz \& Carneiro, 2003) obtida na análise da variância.

Para ilustrar a relação entre as subamostras, mediante dendrogramas, foram testados, inicialmente, os métodos de agrupamento de ligação simples (vizinho mais próximo), ligação completa (vizinho mais distante), Ward, mediana (WPGMA), ligação média entre grupos (UPGMA), Grower (WPGMC), ligação média dentro de grupo e centroide (UPGMC). Para a escolha do melhor método de agrupamento, além da verificação visual e da interpretação dos resultados, calculou-se o coeficiente de correlação cofenética (CCC), de acordo com Sokal \& Rohlf (1962). Para a matriz de distância euclidiana média, relativa às variáveis multicategóricas, escolheu-se o método UPGMA e, para a matriz de distância de Mahalanobis (variáveis quantitativas), optou-se pelo método de ligação completa (vizinho mais distante). Para os dois tipos de variáveis foi obtida a contribuição relativa dos caracteres para divergência genética (CRDG), pelo método de Singh (1981). As análises estatísticas foram realizadas pelo programa Genes (Cruz, 2006).

\section{RESULTADOS E DISCUSSÃO}

As 71 subamostras não diferiram quanto a cinco variáveis multicategóricas, que mostraram ser monomórficas quanto à forma das glumas (pontiaguda), pilosidade das glumas (ausente), cerosidade do lema (presença), posição das espiguetas (ereta) e casca nos grãos (presença). Para os demais caracteres, houve divergência entre as subamostras (Tabelas 2 e 5), cuja variabilidade genética pode ser verificada pela distribuição das frequências das categorias de classificação dentro de cada caractere (Tabela 3).

Entre os caracteres que mostraram maior amplitude na distribuição de frequência destacaram-se: posição das ramificações, pilosidade do nó superior, pilosidade da base do grão, cor do lema e ciclo (Tabela 3). Quanto à posição das ramificações na panícula, 72,3\% do germoplasma apresentaram posição horizontal e 5,6\% decumbente, havendo variabilidade intraespecífica para esse caractere. A. abyssinica mostrou subamostras com os dois extremos, sendo $10 \%$ decumbentes e $2,5 \%$ eretas, mas $50 \%$ se caracterizaram pela posição horizontal das ramificações. $A$. barbata e A. sterilis apresentaram 14\% das subamostras com posição decumbente, $72 \%$ com posição horizontal e o restante (14\%), com posição ereta à semiereta. Para $A$. brevis, $85 \%$ das subamostras mostraram posição semiereta e $15 \%$ ereta, e em A. vaviloviana, $14 \%$ do germoplasma apresentaram posição horizontal e, o restante, semidecumbente.

Quanto à pilosidade do nó superior, 97,2\% das subamostras foram glabras, com exceção de WIR 5226/5 (A. brevis) e CAV 1008 (A. sterilis). A pilosidade na base do grão variou de ausente ou muito fraca $(59,1 \%)$ a muito forte $(19,7 \%)$. Das subamostras com forte pilosidade, $36 \%$ pertenceram à $A$. barbata, $27 \%$ à $A$. vaviloviana, $18 \%$ à $A$. sterilis, com um representante de $A$. brevis e um de $A$. longiglumis. No melhoramento genético de aveia, o objetivo é reduzir a pilosidade do grão, pois isso dificulta a colheita e a limpeza, reduz o peso hectolitro, além de desenvolver carga eletrostática, o que atrai fungos à semente (Floss, 1988). Por essas razões, os bancos de genes e as coleções de melhoramento buscam variedades glabras. Neste estudo, nas subamostras que mostraram pilosidade no grão, em 52,1\% os pelos foram curtos (Tabela 3).

A característica morfológica mais óbvia em aveia é a cor do lema (Coffman, 1964). No presente trabalho, a maioria das subamostras apresentou lema amarelo, seguido do preto e do marrom. Nas subamostras hexaploides, o exemplar de A. fatua se caracterizou pelo lema preto, o que é descrito para a espécie (Luby \& Stuthman, 1983). Na outra espécie hexaploide, A. sterilis, as subamostras apresentaram cor amarela, marrom, cinza e preta, concordando com relato de Coffman (1964) sobre a variabilidade desse atributo na espécie.

Quanto à orientação das ramificações, que identifica a forma da panícula, a maioria das subamostras $(71,8 \%)$ apresentou-se como equilateral. Segundo Mcginnis \& Lin (1966), esse atributo é um importante marcador em aveia, pois o gene que afeta a forma da panícula está ligado ao que é responsável pela produção de clorofila, ou seja, para o albinismo. O ciclo variou de 73 a 121 dias, mas a maioria das subamostras $(52,1 \%)$ mostrou ciclo tardio a muito tardio, florescendo entre 115 e 121 dias após a emergência. Foram enquadradas como precoces a muito precoces 7,0 a 9,9\% das subamostras respectivamente. Nos dois extremos, houve representação de A. vaviloviana, bem como de A. abyssinica, o que era esperado em virtu- 


\begin{tabular}{|c|c|c|c|c|c|c|c|c|c|c|c|c|c|c|c|c|c|c|}
\hline \multirow{2}{*}{ Identificação } & \multirow{2}{*}{ Espécie } & \multicolumn{17}{|c|}{ Caractere $^{1}$} \\
\hline & & PBFI & PBFB & FBR & PFB & PR & OR & PINS & IPINS & ICL & PIGR & CPB & CR & PIL & CL & TA & GR & CI \\
\hline$\overline{\text { CLAV } 3436}$ & ABR & 3 & 1 & 7 & 1 & 3 & 3 & 1 & 1 & 5 & 1 & 3 & 7 & 1 & 5 & 3 & 1 & 9 \\
\hline IPFA 99002 & $\mathrm{ABR}$ & 3 & 1 & 1 & 1 & 3 & 3 & 1 & 1 & 3 & 1 & 3 & 7 & 1 & 5 & 3 & 1 & 7 \\
\hline IPFA 99012 & $\mathrm{ABR}$ & 3 & 1 & 7 & 1 & 3 & 3 & 1 & 1 & 1 & 1 & 3 & 7 & 1 & 3 & 1 & 1 & 7 \\
\hline IPFA 99013 & $\mathrm{ABR}$ & 3 & 1 & 7 & 3 & 3 & 3 & 1 & 1 & 3 & 1 & 3 & 7 & 1 & 5 & 1 & 1 & 5 \\
\hline TÚRGIDA & $\mathrm{ABR}$ & 3 & 1 & 9 & 1 & 5 & 3 & 1 & 1 & 1 & 1 & 3 & 7 & 1 & 3 & 1 & 2 & 7 \\
\hline WIR 5226/5 & $\mathrm{ABR}$ & 3 & 3 & 7 & 3 & 1 & 2 & 2 & 5 & 1 & 1 & 3 & 7 & 1 & 3 & 3 & 2 & 9 \\
\hline WIR 5229 & $\mathrm{ABR}$ & 3 & 1 & 7 & 3 & 3 & 3 & 1 & 1 & 3 & 9 & 5 & 5 & 2 & 2 & 1 & 2 & 5 \\
\hline CW 53 & $\mathrm{AL}$ & 3 & 1 & 9 & 1 & 5 & 2 & 1 & 1 & 3 & 9 & 5 & 5 & 2 & 2 & 1 & 2 & 7 \\
\hline KM 16256 & $\mathrm{AL}$ & 3 & 1 & 9 & 3 & 3 & 3 & 1 & 1 & 3 & 1 & 3 & 7 & 2 & 5 & 1 & 2 & 5 \\
\hline CD 8024 & AW & 3 & 1 & 7 & 1 & 5 & 3 & 1 & 1 & 3 & 1 & 3 & 7 & 2 & 5 & 1 & 1 & 5 \\
\hline BDZA 461 & $\mathrm{AF}$ & 3 & 1 & 9 & 3 & 5 & 3 & 1 & 1 & 3 & 7 & 5 & 7 & 2 & 5 & 2 & 2 & 9 \\
\hline CAV 1008 & AST & 3 & 1 & 7 & 1 & 5 & 3 & 2 & 5 & 3 & 9 & 5 & 5 & 1 & 4 & 1 & 1 & 9 \\
\hline CAV 1878 & $\mathrm{AST}$ & 3 & 3 & 7 & 3 & 1 & 2 & 1 & 1 & 3 & 3 & 5 & 7 & 1 & 2 & 1 & 2 & 9 \\
\hline CAV 3293 & AST & 5 & 3 & 9 & 1 & 5 & 3 & 1 & 1 & 1 & 5 & 7 & 5 & 2 & 5 & 1 & 1 & 7 \\
\hline CAV 3361 & AST & 3 & 1 & 7 & 1 & 5 & 3 & 1 & 1 & 5 & 1 & 3 & 7 & 1 & 2 & 1 & 2 & 7 \\
\hline CLAV 8341 & AST & 3 & 1 & 9 & 1 & 7 & 2 & 1 & 1 & 1 & 5 & 7 & 7 & 2 & 5 & 1 & 2 & 7 \\
\hline CLAV 8342 & AST & 3 & 3 & 9 & 3 & 5 & 2 & 1 & 1 & 3 & 9 & 7 & 9 & 2 & 3 & 1 & 3 & 7 \\
\hline WAHL \# 7 & AST & 3 & 1 & 7 & 5 & 5 & 2 & 1 & 1 & 3 & 9 & 5 & 7 & 2 & 3 & 1 & 3 & 7 \\
\hline CAV 0542 & $\mathrm{AB}$ & 3 & 1 & 9 & 3 & 5 & 2 & 1 & 1 & 3 & 9 & 7 & 7 & 2 & 2 & 1 & 3 & 7 \\
\hline D-106 & $\mathrm{AB}$ & 7 & 5 & 9 & 3 & 5 & 3 & 1 & 1 & 3 & 9 & 5 & 5 & 2 & 3 & 1 & 1 & 5 \\
\hline D-116 & $\mathrm{AB}$ & 3 & 1 & 9 & 1 & 5 & 3 & 1 & 1 & 3 & 9 & 5 & 7 & 2 & 3 & 1 & 2 & 9 \\
\hline D-119 & $\mathrm{AB}$ & 5 & 7 & 9 & 5 & 5 & 3 & 1 & 1 & 3 & 9 & 5 & 7 & 2 & 5 & 1 & 2 & 7 \\
\hline D-120 & $\mathrm{AB}$ & 5 & 7 & 7 & 1 & 7 & 3 & 1 & 1 & 3 & 7 & 3 & 5 & 2 & 3 & 1 & 1 & 5 \\
\hline D-125 & $\mathrm{AB}$ & 5 & 7 & 9 & 1 & 3 & 3 & 1 & 1 & 3 & 1 & 3 & 7 & 2 & 5 & 1 & 2 & 9 \\
\hline CAV 2879 & AV & 3 & 3 & 7 & 1 & 7 & 2 & 1 & 1 & 3 & 7 & 5 & 5 & 2 & 5 & 1 & 1 & 5 \\
\hline CAV 2891 & $\mathrm{AV}$ & 5 & 3 & 7 & 3 & 7 & 2 & 1 & 1 & 3 & 7 & 5 & 7 & 2 & 3 & 1 & 2 & 5 \\
\hline CAV 2907 & AV & 3 & 1 & 9 & 3 & 7 & 2 & 1 & 1 & 1 & 9 & 5 & 7 & 2 & 2 & 1 & 1 & 9 \\
\hline CAV 2921 & $\mathrm{AV}$ & 3 & 1 & 9 & 3 & 7 & 2 & 1 & 1 & 3 & 9 & 5 & 5 & 2 & 2 & 1 & 1 & 9 \\
\hline CAV 3258 & $\mathrm{AV}$ & 3 & 5 & 9 & 3 & 7 & 2 & 1 & 1 & 3 & 9 & 5 & 7 & 2 & 5 & 1 & 2 & 5 \\
\hline CAV 3309 & $\mathrm{AV}$ & 3 & 3 & 7 & 3 & 5 & 3 & 1 & 1 & 5 & 9 & 7 & 7 & 1 & 4 & 1 & 2 & 1 \\
\hline WIR 779 & AV & 3 & 3 & 7 & 3 & 7 & 2 & 1 & 1 & 3 & 7 & 5 & 7 & 2 & 3 & 1 & 2 & 5 \\
\hline CAV 2861 & AA & 3 & 1 & 7 & 1 & 5 & 3 & 1 & 1 & 3 & 5 & 7 & 7 & 1 & 2 & 3 & 2 & 7 \\
\hline CAV 2865 & AA & 3 & 1 & 7 & 1 & 5 & 3 & 1 & 1 & 1 & 3 & 7 & 7 & 1 & 1 & 0 & 2 & 7 \\
\hline CAV 2939 & AA & 3 & 3 & 9 & 1 & 7 & 3 & 1 & 1 & 3 & 1 & 3 & 7 & 1 & 4 & 1 & 2 & 5 \\
\hline CAV 2964 & AA & 7 & 3 & 9 & 3 & 7 & 3 & 1 & 1 & 1 & 1 & 3 & 7 & 1 & 3 & 1 & 2 & 5 \\
\hline CAV 3076 & $\mathrm{AA}$ & 3 & 1 & 9 & 3 & 3 & 3 & 1 & 1 & 3 & 1 & 3 & 7 & 1 & 2 & 1 & 2 & 7 \\
\hline CAV 3105 & $\mathrm{AA}$ & 3 & 1 & 9 & 1 & 5 & 3 & 1 & 1 & 3 & 1 & 3 & 7 & 1 & 2 & 1 & 2 & 7 \\
\hline CAV 3122 & AA & 3 & 3 & 9 & 3 & 3 & 3 & 1 & 1 & 5 & 1 & 3 & 7 & 2 & 2 & 2 & 2 & 5 \\
\hline CAV 3125 & $\mathrm{AA}$ & 5 & 3 & 7 & 3 & 5 & 3 & 1 & 1 & 1 & 1 & 5 & 7 & 1 & 4 & 2 & 2 & 5 \\
\hline CAV 3128 & AA & 3 & 1 & 7 & 3 & 3 & 3 & 1 & 1 & 3 & 1 & 3 & 7 & 1 & 3 & 1 & 2 & 9 \\
\hline
\end{tabular}


Tabela 2. Continuação...

\begin{tabular}{|c|c|c|c|c|c|c|c|c|c|c|c|c|c|c|c|c|c|c|}
\hline \multirow{2}{*}{ Identificação } & \multirow{2}{*}{ Espécie } & \multicolumn{17}{|c|}{ Caractere $^{1}$} \\
\hline & & PBFI & PBFB & FBR & PFB & PR & OR & PINS & IPINS & ICL & PIGR & CPB & CR & PIL & CL & TA & GR & CI \\
\hline CAV 3130 & AA & 3 & 3 & 7 & 1 & 5 & 3 & 1 & 1 & 3 & 1 & 7 & 7 & 1 & 2 & 1 & 2 & 3 \\
\hline CAV 3132 & AA & 3 & 1 & 7 & 3 & 7 & 3 & 1 & 1 & 3 & 1 & 3 & 7 & 1 & 2 & 1 & 2 & 3 \\
\hline CAV 3134 & AA & 3 & 1 & 7 & 3 & 7 & 3 & 1 & 1 & 3 & 1 & 3 & 7 & 1 & 2 & 1 & 2 & 1 \\
\hline CAV 3135 & $\mathrm{AA}$ & 3 & 1 & 7 & 3 & 5 & 3 & 1 & 1 & 3 & 1 & 3 & 7 & 1 & 2 & 1 & 2 & 1 \\
\hline CAV 3139 & $\mathrm{AA}$ & 5 & 5 & 7 & 3 & 7 & 3 & 1 & 1 & 1 & 1 & 5 & 7 & 2 & 4 & 2 & 2 & 5 \\
\hline CAV 3144 & $\mathrm{AA}$ & 3 & 1 & 9 & 1 & 5 & 3 & 1 & 1 & 1 & 1 & 3 & 7 & 1 & 2 & 1 & 2 & 7 \\
\hline CAV 3161 & $\mathrm{AA}$ & 3 & 1 & 9 & 1 & 5 & 3 & 1 & 1 & 5 & 1 & 3 & 7 & 1 & 2 & 1 & 2 & 7 \\
\hline CAV 3233 & AA & 3 & 1 & 7 & 3 & 5 & 3 & 1 & 1 & 3 & 1 & 3 & 7 & 1 & 2 & 1 & 2 & 3 \\
\hline CAV 3238 & AA & 3 & 1 & 7 & 3 & 9 & 3 & 1 & 1 & 1 & 1 & 3 & 7 & 1 & 5 & 1 & 2 & 1 \\
\hline CAV 3241 & AA & 3 & 1 & 9 & 3 & 9 & 2 & 1 & 1 & 5 & 9 & 5 & 5 & 2 & 5 & 1 & 1 & 5 \\
\hline CAV 3244 & $\mathrm{AA}$ & 3 & 3 & 9 & 3 & 9 & 2 & 1 & 1 & 3 & 7 & 5 & 5 & 2 & 2 & 1 & 2 & 5 \\
\hline CAV 3247 & $\mathrm{AA}$ & 3 & 3 & 7 & 3 & 7 & 2 & 1 & 1 & 1 & 1 & 3 & 7 & 1 & 5 & 1 & 2 & 5 \\
\hline CD 7844 & AA & 3 & 3 & 9 & 1 & 7 & 3 & 1 & 1 & 3 & 1 & 3 & 7 & 2 & 2 & 1 & 2 & 5 \\
\hline CD 7845 & AA & 3 & 3 & 7 & 3 & 7 & 3 & 1 & 1 & 3 & 1 & 3 & 7 & 1 & 3 & 1 & 2 & 3 \\
\hline CLAV 2109 & AA & 3 & 1 & 7 & 3 & 7 & 3 & 1 & 1 & 3 & 1 & 3 & 7 & 1 & 2 & 1 & 2 & 1 \\
\hline IPFA 99003 & AA & 3 & 1 & 7 & 1 & 3 & 3 & 1 & 1 & 3 & 1 & 3 & 7 & 1 & 5 & 2 & 1 & 7 \\
\hline IPFA 99014 & AA & 3 & 1 & 9 & 1 & 5 & 3 & 1 & 1 & 5 & 3 & 7 & 7 & 1 & 1 & 0 & 2 & 7 \\
\hline IPFA 99015 & $\mathrm{AA}$ & 3 & 1 & 7 & 1 & 5 & 3 & 1 & 1 & 5 & 3 & 7 & 7 & 1 & 1 & 1 & 2 & 7 \\
\hline IPFA 99016 & $\mathrm{AA}$ & 3 & 1 & 9 & 1 & 5 & 3 & 1 & 1 & 1 & 3 & 7 & 7 & 1 & 1 & 1 & 2 & 7 \\
\hline IPFA 99017 & $\mathrm{AA}$ & 3 & 1 & 7 & 1 & 5 & 3 & 1 & 1 & 3 & 1 & 7 & 7 & 1 & 2 & 1 & 2 & 7 \\
\hline IPFA 99018 & $\mathrm{AA}$ & 3 & 1 & 9 & 1 & 5 & 3 & 1 & 1 & 3 & 3 & 7 & 7 & 1 & 2 & 1 & 2 & 7 \\
\hline IPFA 99019 & $\mathrm{AA}$ & 3 & 1 & 7 & 1 & 5 & 3 & 1 & 1 & 1 & 1 & 3 & 7 & 1 & 2 & 1 & 2 & 7 \\
\hline IPFA 99020 & $\mathrm{AA}$ & 3 & 3 & 9 & 3 & 5 & 3 & 1 & 1 & 5 & 1 & 3 & 7 & 1 & 5 & 1 & 2 & 5 \\
\hline IPFA 99032 & $\mathrm{AA}$ & 3 & 3 & 7 & 3 & 9 & 3 & 1 & 1 & 3 & 1 & 3 & 7 & 2 & 5 & 1 & 2 & 1 \\
\hline IPFA 99034 & AA & 3 & 1 & 7 & 1 & 5 & 3 & 1 & 1 & 1 & 1 & 7 & 7 & 1 & 1 & 1 & 2 & 7 \\
\hline IPFA 99037 & AA & 5 & 5 & 9 & 1 & 5 & 3 & 1 & 1 & 1 & 1 & 3 & 7 & 1 & 4 & 1 & 2 & 5 \\
\hline IPFA 99038 & AA & 3 & 1 & 9 & 1 & 5 & 3 & 1 & 1 & 5 & 1 & 7 & 7 & 1 & 2 & 2 & 2 & 7 \\
\hline K 5104 & AA & 7 & 3 & 7 & 3 & 7 & 3 & 1 & 1 & 3 & 1 & 3 & 7 & 2 & 2 & 1 & 2 & 5 \\
\hline PI 234842 & AA & 3 & 1 & 7 & 3 & 5 & 3 & 1 & 1 & 1 & 1 & 3 & 7 & 1 & 3 & 1 & 2 & 1 \\
\hline PI 258539 & AA & 5 & 3 & 7 & 3 & 7 & 3 & 1 & 1 & 5 & 1 & 3 & 7 & 1 & 5 & 1 & 2 & 3 \\
\hline L. FELLOW & AA & 3 & 3 & 7 & 3 & 1 & 2 & 1 & 1 & 5 & 1 & 3 & 7 & 1 & 1 & 2 & 2 & 9 \\
\hline \multicolumn{19}{|c|}{ 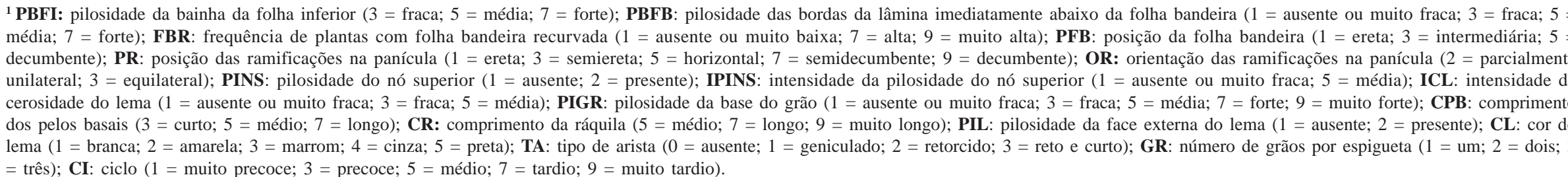 } \\
\hline
\end{tabular}


Tabela 3. Frequência dos caracteres multicategóricos de 71 subamostras de aveias silvestres do Banco Ativo de Germoplasma da Embrapa Trigo

\begin{tabular}{|c|c|c|}
\hline Caractere & Descrição & Frequência $(\%)$ \\
\hline \multirow{3}{*}{ Pilosidade da bainha da folha inferior } & Fraca & 83,0 \\
\hline & Média & 12,7 \\
\hline & Forte & 4,3 \\
\hline \multirow{4}{*}{ Pilosidade das bordas da lâmina imediatamente abaixo da folha bandeira } & Ausente a muito fraca & 59,1 \\
\hline & Fraca & 31,0 \\
\hline & Média & 5,6 \\
\hline & Forte & 4,3 \\
\hline \multirow{3}{*}{ Frequência de plantas com folha bandeira recurvada } & Ausente ou muito baixa & 1,4 \\
\hline & Alta & 54,9 \\
\hline & Muito alta & 43,7 \\
\hline \multirow{3}{*}{ Posição da folha bandeira } & Ereta & 45,1 \\
\hline & Intermediária & 52,1 \\
\hline & Decumbente & 2,8 \\
\hline \multirow{5}{*}{ Posição das ramificações na panícula } & Ereta & 4,3 \\
\hline & Semiereta & 15,5 \\
\hline & Horizontal & 47,8 \\
\hline & Semidecumbente & 26,8 \\
\hline & Decumbente & 5,6 \\
\hline \multirow{2}{*}{ Orientação das ramificações na panícula } & Parcialmente unilateral & 28,2 \\
\hline & Equilateral & 71,8 \\
\hline \multirow{2}{*}{ Pilosidade do nó superior } & Ausente & 97,2 \\
\hline & Presente & 2,8 \\
\hline \multirow{2}{*}{ Intensidade da pilosidade do nó superior } & Ausente ou muito fraca & 98,6 \\
\hline & Média & 1,4 \\
\hline \multirow{3}{*}{ Intensidade da cerosidade do lema } & Muito fraca & 26,7 \\
\hline & Fraca & 57,8 \\
\hline & Média & 15,5 \\
\hline \multirow{5}{*}{ Pilosidade da base do grão primário } & Ausente ou muito fraca & 59,1 \\
\hline & Fraca & 8,5 \\
\hline & Média & 4,2 \\
\hline & Forte & 8,5 \\
\hline & Muito forte & 19,7 \\
\hline \multirow{3}{*}{ Comprimento dos pelos basais do grão primário } & Curto & 52,1 \\
\hline & Médio & 26,8 \\
\hline & Longo & 21,1 \\
\hline \multirow{3}{*}{ Comprimento da ráquila } & Médio & 14,0 \\
\hline & Longo & 84,5 \\
\hline & Muito longo & 1,5 \\
\hline \multirow[b]{2}{*}{ Pilosidade na face externa do lema } & Ausente & 59,2 \\
\hline & Presente & 40,8 \\
\hline \multirow{5}{*}{ Cor do lema } & Branca & 8,4 \\
\hline & Amarela & 36,9 \\
\hline & Marrom & 19,6 \\
\hline & Cinza & 8,4 \\
\hline & Preta & 26,7 \\
\hline \multirow{4}{*}{ Tipo de arista } & Ausente & 2,8 \\
\hline & Geniculado & 81,7 \\
\hline & Retorcido & 9,9 \\
\hline & Reto e curto & 5,6 \\
\hline \multirow{3}{*}{ Número de grãos por espigueta } & $\mathrm{Um}$ & 15,5 \\
\hline & Dois & 80,3 \\
\hline & Três & 4,2 \\
\hline \multirow{5}{*}{ Ciclo } & Muito precoce & 9,9 \\
\hline & Precoce & 7,0 \\
\hline & Médio & 31,0 \\
\hline & Tardio & 36,6 \\
\hline & Muito tardio & 15,5 \\
\hline
\end{tabular}


Tabela 4. Contribuição relativa dos caracteres multicategóricos para a dissimilaridade genética de 71 subamostras de aveias silvestres do Banco Ativo de Germoplasma da Embrapa Trigo, em ordem decrescente de importância pelo método de Singh (1981)

\begin{tabular}{lr}
\hline Caractere & Valor (\%) \\
\hline Pilosidade da base do grão & 32,1606 \\
Ciclo & 15,2822 \\
Posição da ramificação na panícula & 9,4876 \\
Comprimento dos pelos basais do grão & 7,5089 \\
Pilosidade das bordas imediatamente abaixo & 7,3058 \\
da folha bandeira & 5,5112 \\
Cor do lema & 4,9445 \\
Intensidade da cerosidade do lema & 4,8548 \\
Frequência de plantas com folha bandeira recurvada & 3,2822 \\
Posição da folha bandeira & 2,9894 \\
Pilosidade da bainha da folha inferior & 2,0366 \\
Intensidade da pilosidade do nó superior & 1,6529 \\
Comprimento da ráquila & 0,9481 \\
Tipo de arista & 0,7107 \\
Pilosidade da face externa do lema & 0,6411 \\
Número de grãos por espigueta & 0,6021 \\
Orientação das ramificações na panícula & 0,0815 \\
Pilosidade do nó superior &
\end{tabular}

de de essa última ter sido a espécie com o maior número de subamostras. O ciclo é de extrema importância para os programas de melhoramento de aveia-branca, nos quais se busca a redução do tempo entre a emergência e o início do florescimento (Amaral et al., 1996), a fim de permitir seu cultivo sem competir com as lavouras de verão (Kurek et al., 2002).

A contribuição relativa dos caracteres multicategóricos para divergência genética (CRDG) variou de $0,081 \%$ (pilosidade do nó superior do colmo) a 32,16\% (pilosidade da base do grão) (Tabela 4). O segundo caractere com maior CRDG foi o ciclo, com 15,28\% de contribuição. A pilosidade do nó superior do colmo teve pequena contribuição, em virtude da elevada frequência de subamostras com nós glabros $(95,7 \%)$; apenas duas subamostras apresentaram pilosidade no nó superior do colmo.

Entre os métodos de agrupamento testados, o UPGMA representou de forma mais adequada a matriz de distância euclidiana, com coeficiente de correlação cofenética (CCC) de 0,88 , valor que representa alta correlação (Sokal \& Rohlf, 1962). Os dendrogramas construídos a partir da matriz dos índices de similaridade (IS) apresentaram baixos valores cofenéticos e, por isso, não foram apresentados. No dendrograma construído pelo método UPGMA, a partir da matriz de distância euclidiana média, com base nas variáveis multicategóricas, as subamostras formaram quatro grupos (Figura 1), considerando-se como ponto de corte $60 \%$ de distância relativa entre as subamostras.

Não existe critério objetivo para determinar o ponto de corte em dendrogramas (Albuquerque et al., 2006), sendo que, nos agrupamentos hierárquicos, a delimitação dos grupos é feita de maneira subjetiva, observandose pontos de alta mudança de nível no dendrograma e, por isso, diferentes padrões de agrupamento podem ocorrer (Arriel et al., 2006). A adequação do UPGMA para agrupar as subamostras da coleção ficou evidenciada, principalmente, pelo isolamento das duas subamostras da coleção que apresentaram pilosidade no nó superior do colmo, WIR 5226/5 (A. brevis) e CAV 1008 (A. sterilis), nos grupos 3 e 4 , respectivamente (Figura 1). Esse método de agrupamento é considerado o mais simples para a construção de árvores filogenéticas, sendo utilizado com frequência no estudo da variabilidade de germoplasma de diversas culturas (Bertam et al., 2006; Vendramini et al., 2011), e, especialmente, para germoplasma silvestre (Cruz $\&$ Carneiro, 2003).

Entre as subamostras alocadas individualmente, CAV 1008 destacou-se por ser um dos dois materiais a apresentar pilosidade no nó superior do colmo, além de intensa pilosidade na base do grão. Essa subamostra mostrou comprimento médio da ráquila, ao passo que nas demais subamostras houve predomínio de ráquila longa. Já as duas subamostras de A. brevis, WIR 5226/5 (grupo 3) e IPFA 99002 (grupo 2) diferiram quanto a 11 caracteres multicategóricos. IPFA 99002, procedente do Brasil, apresentou folha bandeira ereta e não recurvada, ramificações semieretas e equilaterais, ausência de pelos no nó superior, lema preto e ciclo tardio. WIR 5226/5, de Portugal, mostrou folha bandeira recurvada, posição intermediária da folha bandeira, ramificações da panícula parcialmente unilaterais, pilosidade do nó superior, lema marrom e ciclo muito tardio.

O grupo 1 alocou 96\% das subamostras e foi dividido em três subgrupos: o subgrupo $1 \mathrm{a}$ - incluiu as subamostras com grãos glabros e ciclo tardio; o subgrupo $1 \mathrm{~b}-$ caracterizou-se pela forte pilosidade da base do grão e ciclo médio; no subgrupo 1c - a maioria das subamostras foi de ciclo médio e sem pilosidade na base do grão (Figura 1). O subgrupo 1a foi formado por 33 subamostras de $A$. abysinica, o que representou $82,5 \%$ do total das subamostras dessa espécie no conjunto avaliado. No subgrupo $1 \mathrm{~b}$, permaneceram seis das sete subamostras de $A$. vaviloviana e, no subgrupo 1c, quatro dos seis representantes de A. barbata.

Os valores da distância euclidiana média (D) indicaram as subamostras CAV 3241 (A. abyssinica) e WIR 5226/ 5 (A. brevis) como as mais divergentes $(\mathrm{D}=2,93)$. A maior similaridade $(D=0)$ foi verificada entre duas subamostras de A. abyssinica, oriundas da Etiópia, CAV 3134 e CLAV 2109, sugerindo ser duplicata, hipótese também corroborada pelo índice de similaridade ( $I S=1.0)$. O menor índice de similaridade (IS $=0,11$ ) ocorreu entre quatro pares de subamostras: WIR 5226/5 (A. brevis) e CAV 3293 (A. sterilis), D-106 e D-119, D-106 e D-120 e D-119 e D- 120, 
Tabela 5. Médias do comprimento médio de planta, panícula e gluma de 71 subamostras de aveias silvestres do Banco Ativo de Germoplasma da Embrapa Trigo e grupos estabelecidos pelo método de agrupamento hierárquico de ligação completa (vizinho mais distante) com base na matriz de distância de Mahalanobis

\begin{tabular}{|c|c|c|c|c|c|}
\hline Subamostra & Espécie $^{1}$ & Planta (cm) & Panícula (cm) & Gluma (mm) & Grupo \\
\hline $\mathrm{D}-125$ & $\mathrm{AB}$ & $194,0 \mathrm{a}$ & $37,2 \mathrm{c}$ & $20,2 \mathrm{~g}$ & 1 \\
\hline D-116 & $\mathrm{AB}$ & $177,5 \mathrm{~b}$ & $40,7 \mathrm{~b}$ & $21,0 \mathrm{f}$ & 1 \\
\hline D-120 & $\mathrm{AB}$ & $176,8 \mathrm{~b}$ & $33,3 \mathrm{c}$ & $18,4 \mathrm{~g}$ & 1 \\
\hline D-119 & $\mathrm{AB}$ & $171,0 \mathrm{~b}$ & $41,2 \mathrm{~b}$ & $24,9 \mathrm{e}$ & 1 \\
\hline D-106 & $\mathrm{AB}$ & $167,2 \mathrm{~b}$ & $36,3 \mathrm{c}$ & $20,5 \mathrm{f}$ & 1 \\
\hline CAV 1008 & AST & $166,0 \mathrm{~b}$ & $40,0 \mathrm{~b}$ & $21,3 \mathrm{f}$ & 1 \\
\hline LONG FELLOW (WIR 2566) & AA & $163,8 \mathrm{~b}$ & $33,3 \mathrm{c}$ & $27,1 \mathrm{~d}$ & 1 \\
\hline WIR $5226 / 5$ & ABR & $161,5 \mathrm{~b}$ & $36,5 \mathrm{c}$ & $17,4 \mathrm{~h}$ & 1 \\
\hline TÚRGIDA & $\mathrm{ABR}$ & $152,2 \mathrm{c}$ & $27,0 \mathrm{~d}$ & $18,4 \mathrm{~g}$ & 1 \\
\hline IPFA 99002 & $\mathrm{ABR}$ & $149,0 \mathrm{c}$ & $22,8 \mathrm{e}$ & $15,4 \mathrm{~h}$ & 1 \\
\hline CAV 1878 & AST & $147,7 \mathrm{c}$ & $50,5 \mathrm{a}$ & $20,8 \mathrm{f}$ & 2 \\
\hline CAV 0542 & $\mathrm{AB}$ & $144,3 \mathrm{c}$ & $35,8 \mathrm{c}$ & $37,1 \mathrm{a}$ & 3 \\
\hline IPFA 99019 & AA & $138,8 \mathrm{c}$ & $30,8 \mathrm{c}$ & $23,9 \mathrm{e}$ & 1 \\
\hline WAHL \# 7 & AST & $138,0 \mathrm{c}$ & $30,3 \mathrm{c}$ & $29,7 \mathrm{c}$ & 3 \\
\hline CAV 3161 & $\mathrm{AA}$ & $137,5 \mathrm{c}$ & $30,8 \mathrm{c}$ & $23,0 \mathrm{e}$ & 1 \\
\hline CAV 3361 & AST & $135,8 \mathrm{c}$ & $30,7 \mathrm{c}$ & $23,3 \mathrm{e}$ & 1 \\
\hline BDZA 461 & $\mathrm{AF}$ & $133,5 \mathrm{c}$ & $22,5 \mathrm{e}$ & $25,9 \mathrm{~d}$ & 1 \\
\hline CAV 3076 & AA & $133,0 \mathrm{c}$ & $33,7 \mathrm{c}$ & $23,2 \mathrm{e}$ & 1 \\
\hline CLAV 3436 & $\mathrm{ABR}$ & $131,7 \mathrm{c}$ & $21,3 \mathrm{e}$ & $15,8 \mathrm{~h}$ & 1 \\
\hline IPFA 99038 & AA & $131,3 \mathrm{c}$ & $28,3 \mathrm{~d}$ & $23,6 \mathrm{e}$ & 1 \\
\hline CLAV 8342 & AST & $129,9 \mathrm{c}$ & $28,8 \mathrm{~d}$ & $32,5 \mathrm{~b}$ & 3 \\
\hline CAV 2861 & $\mathrm{AA}$ & $127,8 \mathrm{c}$ & $25,2 \mathrm{~d}$ & $24,1 \mathrm{e}$ & 1 \\
\hline CAV 2865 & AA & $127,2 \mathrm{c}$ & $27,5 \mathrm{~d}$ & $22,8 \mathrm{e}$ & 1 \\
\hline IPFA 99003 & AA & $124,3 \mathrm{~d}$ & $21,5 \mathrm{e}$ & $17,7 \mathrm{~h}$ & 1 \\
\hline CAV 3132 & AA & $124,0 \mathrm{~d}$ & $28,8 \mathrm{~d}$ & $20,6 \mathrm{f}$ & 1 \\
\hline IPFA 99037 & AA & $123,3 \mathrm{~d}$ & $32,7 \mathrm{c}$ & $23,2 \mathrm{e}$ & 1 \\
\hline CAV 3105 & AA & $123,0 \mathrm{~d}$ & $24,3 \mathrm{e}$ & $22,6 \mathrm{e}$ & 1 \\
\hline WIR 5229 & ABR & $122,7 \mathrm{~d}$ & $22,8 \mathrm{e}$ & $27,9 \mathrm{~d}$ & 1 \\
\hline CLAV 8341 & AST & $122,3 \mathrm{~d}$ & $31,2 \mathrm{c}$ & $28,8 \mathrm{c}$ & 3 \\
\hline IPFA 99016 & $\mathrm{AA}$ & $121,3 \mathrm{~d}$ & $23,5 \mathrm{e}$ & $23,3 \mathrm{e}$ & 1 \\
\hline CAV 3293 & AST & $120,0 \mathrm{~d}$ & $26,8 \mathrm{~d}$ & $17,2 \mathrm{~h}$ & 1 \\
\hline IPFA 99018 & $\mathrm{AA}$ & $117,7 \mathrm{~d}$ & $22,7 \mathrm{e}$ & $23,0 \mathrm{e}$ & 1 \\
\hline CAV 3144 & AA & $116,8 \mathrm{~d}$ & $28,5 \mathrm{~d}$ & $21,1 \mathrm{f}$ & 1 \\
\hline KM 16256 & $\mathrm{AL}$ & $116,7 \mathrm{~d}$ & $20,8 \mathrm{e}$ & $16,9 \mathrm{~h}$ & 1 \\
\hline IPFA 99034 & $\mathrm{AA}$ & $116,2 \mathrm{~d}$ & $20,4 \mathrm{e}$ & $21,4 \mathrm{f}$ & 1 \\
\hline CAV 2964 & AA & $116,0 \mathrm{~d}$ & $30,3 \mathrm{c}$ & $21,2 \mathrm{f}$ & 1 \\
\hline IPFA 99014 & AA & $114,8 \mathrm{~d}$ & $24,8 \mathrm{~d}$ & $21,5 \mathrm{f}$ & 1 \\
\hline CAV 3130 & AA & $114,7 \mathrm{~d}$ & $28,2 \mathrm{~d}$ & $21,0 \mathrm{f}$ & 1 \\
\hline IPFA 99012 & $\mathrm{ABR}$ & $114,5 \mathrm{~d}$ & $22,3 \mathrm{e}$ & $15,3 \mathrm{~h}$ & 1 \\
\hline IPFA 99015 & AA & $114,0 \mathrm{~d}$ & $23,2 \mathrm{e}$ & $23,1 \mathrm{e}$ & 1 \\
\hline IPFA 99013 & $\mathrm{ABR}$ & $113,8 \mathrm{~d}$ & $23,3 \mathrm{e}$ & $15,3 \mathrm{~h}$ & 1 \\
\hline CD 8024 & AW & $113,1 \mathrm{~d}$ & $25,7 \mathrm{~d}$ & $17,4 \mathrm{~h}$ & 1 \\
\hline CAV 2939 & AA & $107,8 \mathrm{~d}$ & $30,7 \mathrm{c}$ & $19,9 \mathrm{~g}$ & 2 \\
\hline IPFA 99017 & AA & $107,3 \mathrm{~d}$ & $21,3 \mathrm{e}$ & $21,9 \mathrm{f}$ & 1 \\
\hline CAV 3125 & $\mathrm{AA}$ & $107,2 \mathrm{~d}$ & $24,8 \mathrm{~d}$ & $22,0 \mathrm{f}$ & 1 \\
\hline CAV 3139 & AA & $105,8 \mathrm{~d}$ & $22,2 \mathrm{e}$ & $21,9 \mathrm{f}$ & 1 \\
\hline CAV 3244 & $\mathrm{AA}$ & $104,2 \mathrm{~d}$ & $32,8 \mathrm{c}$ & $19,6 \mathrm{~g}$ & 2 \\
\hline CAV 3128 & AA & $102,0 \mathrm{e}$ & $31,0 \mathrm{c}$ & $20,7 \mathrm{f}$ & 2 \\
\hline CAV 3134 & AA & $100,7 \mathrm{e}$ & $33,0 \mathrm{c}$ & $20,1 \mathrm{~g}$ & 2 \\
\hline CAV 2879 & $\mathrm{AV}$ & $100,5 \mathrm{e}$ & $29,0 \mathrm{~d}$ & $19,0 \mathrm{~g}$ & 2 \\
\hline CW 53 & $\mathrm{AL}$ & $100,2 \mathrm{e}$ & $29,7 \mathrm{c}$ & $29,9 c$ & 3 \\
\hline CAV 2907 & AV & $99,8 \mathrm{e}$ & $31,3 \mathrm{c}$ & $20,3 \mathrm{~g}$ & 2 \\
\hline WIR 779 & $\mathrm{AV}$ & $95,7 \mathrm{e}$ & $26,2 \mathrm{~d}$ & $20,8 \mathrm{f}$ & 2 \\
\hline CAV 2921 & $\mathrm{AV}$ & $93,5 \mathrm{e}$ & $26,8 \mathrm{~d}$ & $19,4 \mathrm{~g}$ & 2 \\
\hline CAV 3238 & $\mathrm{AA}$ & $92,3 \mathrm{e}$ & $21,7 \mathrm{e}$ & $20,0 \mathrm{~g}$ & 2 \\
\hline CAV 3309 & $\mathrm{AV}$ & $91,5 \mathrm{e}$ & $25,0 \mathrm{~d}$ & $20,1 \mathrm{~g}$ & 2 \\
\hline CAV 2891 & $\mathrm{AV}$ & $91,0 \mathrm{e}$ & $26,2 \mathrm{~d}$ & $20,0 \mathrm{~g}$ & 2 \\
\hline CAV 3233 & AA & $89,5 \mathrm{e}$ & $27,5 \mathrm{~d}$ & $22,1 \mathrm{f}$ & 2 \\
\hline
\end{tabular}

Rev. Ceres, Viçosa, v. 59, n.5, p. 654-667, set/out, 2012 
Tabela 5. Continuação...

\begin{tabular}{|c|c|c|c|c|c|}
\hline Subamostra & Espécie $^{1}$ & Planta $(\mathrm{cm})$ & Panícula (cm) & Gluma (mm) & Grupo \\
\hline CAV 3122 & AA & $89,3 \mathrm{e}$ & $27,0 \mathrm{~d}$ & $22,4 \mathrm{e}$ & 2 \\
\hline CAV 3258 & $\mathrm{AV}$ & $88,3 \mathrm{e}$ & $24,7 \mathrm{~d}$ & $17,9 \mathrm{~h}$ & 2 \\
\hline CD 7845 & AA & $87,2 \mathrm{e}$ & $23,3 \mathrm{e}$ & $19,0 \mathrm{~g}$ & 2 \\
\hline CD 7844 & AA & $87,0 \mathrm{e}$ & $25,7 \mathrm{~d}$ & $20,8 \mathrm{f}$ & 2 \\
\hline CAV 3135 & AA & $85,2 \mathrm{e}$ & $28,3 \mathrm{~d}$ & $24,7 \mathrm{e}$ & 2 \\
\hline IPFA 99032 & AA & $84,7 \mathrm{e}$ & $19,9 \mathrm{e}$ & $19,4 \mathrm{~g}$ & 2 \\
\hline K 5104 & AA & $84,7 \mathrm{e}$ & $20,8 \mathrm{e}$ & $19,4 \mathrm{~g}$ & 2 \\
\hline CAV 3247 & AA & $84,0 \mathrm{e}$ & $23,8 \mathrm{e}$ & $19,4 \mathrm{~g}$ & 2 \\
\hline PI 258539,5970 & AA & $83,0 \mathrm{e}$ & $27,5 \mathrm{~d}$ & $19,6 \mathrm{~g}$ & 2 \\
\hline CLAV 2109 & AA & $82,3 \mathrm{e}$ & $20,7 \mathrm{e}$ & $18,9 \mathrm{~g}$ & 2 \\
\hline IPFA 99020 & AA & 80,7 e & $21,0 \mathrm{e}$ & $19,4 \mathrm{~g}$ & 2 \\
\hline PI 234842,32 & AA & $78,5 \mathrm{e}$ & $21,0 \mathrm{e}$ & $19,1 \mathrm{~g}$ & 2 \\
\hline CAV 3241 & AA & $73,0 \mathrm{e}$ & $28,0 \mathrm{~d}$ & $19,3 \mathrm{~g}$ & 2 \\
\hline Média \pm DP & & $117,7 \pm 28,2$ & $27,8 \pm 6,3$ & $21,5 \pm 3,9$ & \\
\hline $\mathrm{CV}(\%)$ & & 8,3 & 11,6 & 6,2 & \\
\hline
\end{tabular}

sendo estes três últimos pares de $A$. barbata. As principais divergências foram no tipo de arista, pilosidade do grão, orientação das ramificações na panícula e posição das ramificações.

Para as variáveis quantitativas, a análise de variância revelou diferença significativa entre as subamostras, indicando variabilidade para comprimento de planta, panícula e glumas. As comparações das médias para essas características são apresentadas na Tabela 5 . O comprimento das plantas variou de 73 a $194 \mathrm{~cm}$, com as seguintes frequências no conjunto de subamostras: curta $=$ $19,7 \%$; média $=21,1 \%$; longa $=30,9 \%$; e muito longa $=$ $28,3 \%$. No melhoramento de aveia-branca, a estatura de planta foi um caráter que sofreu forte pressão de seleção, em decorrência da busca por cultivares de menor estatura, para evitar o acamamento (Kurek et al., 2002), sendo estimados $31 \%$ de redução na altura das plantas, entre variedades antigas e modernas (Barbosa Neto et al., 2000). Segundo Morikawa (1989), em Avena spp. são consideradas plantas anãs aquelas com estatura inferior a $90 \mathrm{~cm}$ e que possuem o segundo entrenó extremamente curto. Neste estudo, 14 subamostras mostraram altura inferior a $90 \mathrm{~cm}$, sendo todas $A$. abyssinica, o que incluiu dois materiais com altura inferior a $80 \mathrm{~cm}$, indicando ser uma importante fonte de genes para baixa estatura. A importância dessa espécie decorre do fato de que representa raças rapidamente evoluídas, que são capazes de trocar genes com as aveias cultivadas. As subamostras hexaploides, A. sterilis e A. fatua, mostraram comprimento entre $120 \mathrm{e}$ $166 \mathrm{~cm}$, sendo $42,9 \%$ classificadas como longas e $57,2 \%$ muito longas. Os valores observados neste estudo para A. fatua são superiores aos encontrados no germoplasma avaliado por Matiello et al. (1999), que registraram valo- res entre 77 e $128 \mathrm{~cm}$. Essa variação está de acordo com Coffman (1964), que relatou elevada variabilidade nessa espécie para comprimento de planta. Todas as subamostras de $A$. barbata permaneceram na categoria de muito longas, com comprimento entre 144 e $194 \mathrm{~cm}$.

O comprimento de panícula variou entre 19,9 (A. sterilis, CAV 1878) e 50,5 cm (A. abyssinica, IPFA 99032), indicando que todas subamostras apresentaram eixo floral longo ( $\geq 20 \mathrm{~cm})$, de acordo com a classificação de Brasil (2002). Menor comprimento de panícula é uma característica procurada no melhoramento de aveia-branca, pois a redução na inflorescência determina maior número de grãos, aumentando o rendimento (Carvalho \& Federizzi, 1989). O comprimento das glumas variou de 15,3 a 37,1 $\mathrm{mm}$, sendo esses extremos verificados em duas subamostras de A. barbata. O maior valor observado para esse atributo, na subamostra CAV 0542 dessa espécie, superou ao que Zarco (1990) relatou (31 mm) em estudo com populações coletadas na Península Ibérica e Ilhas Baleares. Clausen \& Alonso (1999) avaliaram trinta populações de A. barbata e observaram comprimento de gluma variando entre 18,8 e 21,9 mm, valores que estão dentro da amplitude verificada neste estudo.

$\mathrm{Na}$ análise da divergência genética a partir das variáveis quantitativas, a distância genética entre as subamostras variou de $\mathrm{D}^{2}=0,052$ (CAV 3130 e CAV 3144, ambas $A$. abyssinica) a $\mathrm{D}^{2}=278,27$ (IPFA 99002, A. brevis e CAV 0542, A. barbata). A contribuição relativa para divergência genética foi de $46,7 \%$ do comprimento de planta, $42,3 \%$ do comprimento de gluma e $11,0 \%$ do comprimento de panícula.

No dendrograma (Figura 2) obtido pelo método de ligação completa (vizinho mais distante), as subamostras 


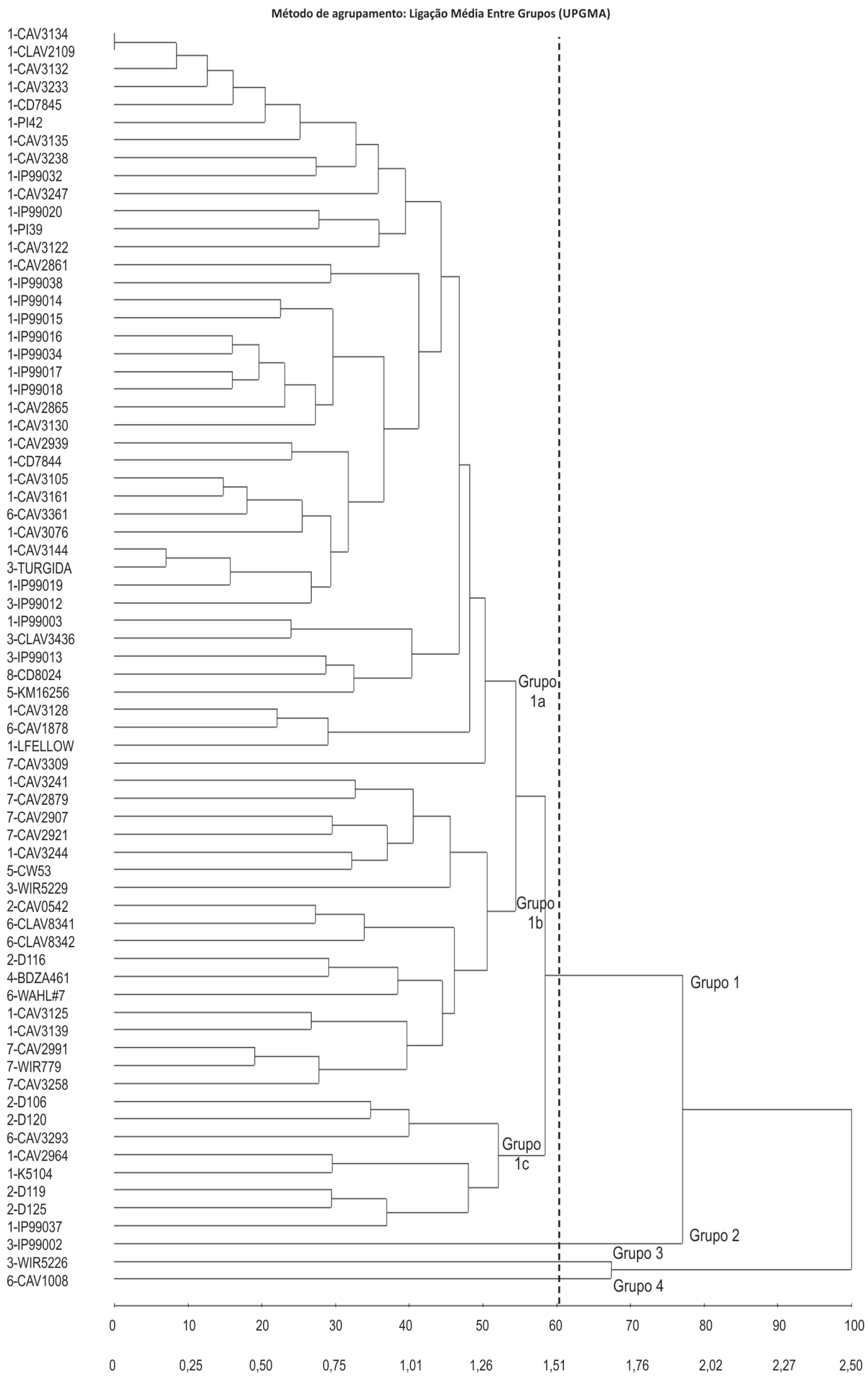

Figura 1. Dendrograma obtido pelo método de agrupamento hierárquico UPGMA, com base na matriz de distância Euclidiana média a partir dos caracteres multicategóricos, de 71 subamostras de aveias silvestres do Banco Ativo de Germoplasma da Embrapa Trigo. No eixo "x" encontram-se as distâncias genéticas relativas e no "y", encontra-se a identificação da subamostra, com número da espécie à esquerda da sigla. $1=$ Avena abyssinica $; 2=$ A. barbata $; 3=$ A. brevis $; 4=$ A. fatua $; 5=$ A. longiglumis $; 6=A$. sterilis; $7=A$. vaviloviana; $8=$ A. wiestii.

Rev. Ceres, Viçosa, v. 59, n.5, p. 654-667, set/out, 2012 


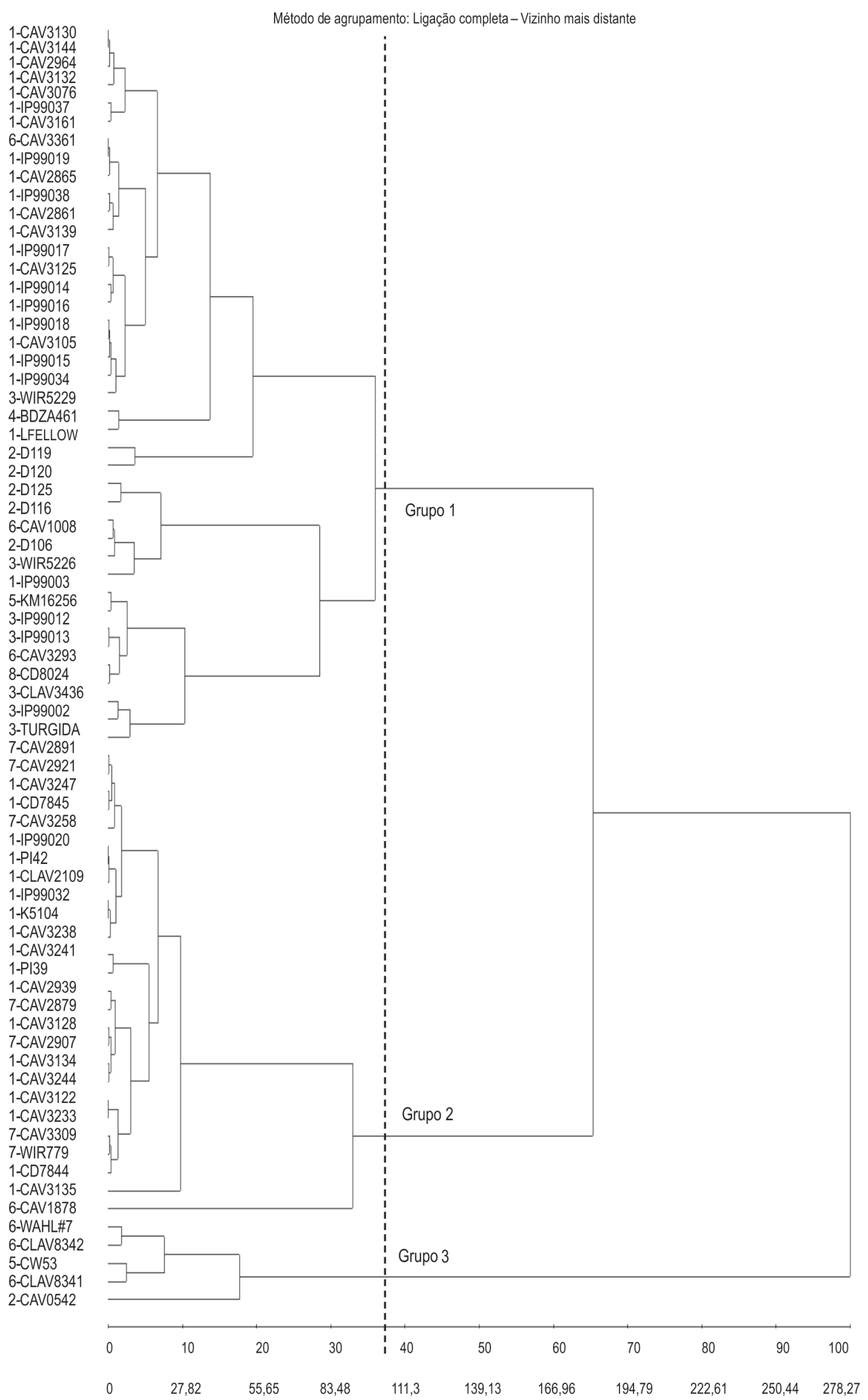

Figura 2. Dendrograma obtido pelo método de agrupamento hierárquico de ligação completa (vizinho mais distante), com base na matriz de distância de Mahalanobis a partir dos caracteres quantitativos de 71 subamostras de aveias silvestres do Banco Ativo de Germoplasma da Embrapa Trigo. No eixo "x”, encontram-se as distâncias genéticas relativas e no "y”, encontra-se a identificação da subamostra, com número da espécie à esquerda da sigla. $1=$ Avena abyssinica $; 2=$ A. barbata $3=$ A. brevis; $4=$ A. fatua $; 5=A$. longiglumis; $6=$ A. sterilis $; 7=$ A. vaviloviana $; 8=$ A. wiestii. . 
foram alocadas em três grupos: o grupo 1, com quarenta subamostras, alocou os materiais com elevados comprimentos de planta $($ média $=131 \mathrm{~cm})$ e panícula $($ média $=28$ $\mathrm{cm}$ ), e comprimento médio de gluma (média $=21 \mathrm{~mm}$ ); o grupo 2, com 26 subamostras, foi formado por materiais com menor comprimento médio de planta $(92 \mathrm{~cm})$, mas com mesma média de comprimento de panícula e valor similar ao comprimento de gluma $(20 \mathrm{~mm})$ das subamostras do grupo 1; no grupo 3, ficaram as subamostras com maior comprimento médio de gluma $(31 \mathrm{~mm})$, mesmo valor médio para comprimento de planta do grupo $1(131 \mathrm{~cm}) \mathrm{e}$ valor similar de comprimento de panícula $(30 \mathrm{~cm})$ das subamostras dos grupos 1 e 2 . Dentre as espécies com maior número de subamostras, A. abyssinica teve $58 \%$ de subamostras agrupadas no grupo 1 e $43 \%$ no grupo 2, enquanto todas as subamostras de $A$. brevis foram agrupadas no grupo 1e de A. vaviloviana no grupo 3 .

\section{CONCLUSÕES}

A coleção de subamostras de aveias silvestres do Banco de Germoplasma da Embrapa Trigo apresenta elevada variabilidade genética para caracteres de interesse no melhoramento de aveias.

\section{AGRADECIMENTOS}

Aos revisores anônimos e aos editores da revista, pelas valiosas sugestões.

\section{REFERÊNCIAS}

Ahokas H \& Manninem ML (2000) Introgressive hexaploid oats from the Avena abyssinica x A. sativa hybrid: performance, grain lipids and proteins. Euphytica, 111:153-160.

Albuquerque MA, Ferreira RLC, Silva JAA da, Santos ESS, Stosic C \& Souza A de (2006) Estabilidade em análise de agrupamento: estudo de caso em ciência florestal. Revista Árvore, 30:257-265.

Amaral ALA, Carvalho FIF, Federizzi LC, Mittelmann A \& Pandini F (1996) Estimativa da herdabilidade para os caracteres adaptativos ciclo e estatura de planta em aveia. Ciência Rural, 26:33-37.

Aung T, Thomas H \& Jones IT (1977) Transfer of gene for mildew resistance from Avena barbata (4x) into cultivated oat Avena sativa by an induced translocation. Euphytica, 26:623-632.

Arriel NHC, Di Mauro AO, Di Mauro SMZ, Bakkes AO, UnêdaTrevisol SH, Costa MM, Capeloto A \& Corrado AR (2006) Técnicas multivariadas na determinação da diversidade genética em gergelim usando marcadores RAPD. Pesquisa Agropecuária Brasileira, 41:801-809.

Barbosa Neto JF, Matiello RR, Carvalho FIF de, Oliveira JMS, Pegoraro DG, Schneider F, Sorde MEB \& Vacaro E (2000) Progresso genético no melhoramento da aveia-branca no sul do Brasil. Pesquisa Agropecuária Brasileira, 35:1605-1612.

Bertam I, Carvalho FIF, Oliveira AC de, Vieira EA, Hartwig I, Silva JAG da, Shimidt DAM, Valério IP, Busato CC \& Ribeiro G (2006) Comparação de métodos de agrupamento na representação da distância morfológica entre genótipos de trigo. Revista Brasileira de Agrociência, 12:279-286.
Biodiversity International (2007) Guidelines for the development of crop descriptor lists. Rome, Bioversity International. 72p. (Bioversity Technical Bulletin Series, 13).

Brasil (2002) Instruções para execução dos ensaios de distinguibilidade, homogeneidade e estabilidade de cultivares de aveia (Avena spp.). Diário Oficial da União, $1^{\circ}$ de março de 2002, seção 1:2-3. Disponível em: <http:// www.agricultura.gov.br>. Acessado em: 16 de maio de 2005.

Carvalho FIF \& Federizzi LC (1989) Evolução da cultura da aveia no sul do Brasil. Trigo e Soja, 102:16-19.

Clausen AM \& Alonso SI (1999) Variabilidad en poblaciones de Avena barbata naturalizadas em diferentes províncias argentinas. Balcarce, INTA. Disponível em: <http://www.inta.gov.ar/ balcarce>. Acessado em: 20 de março de 2011.

Coffman FA (1964) Inheritance of morphologic characters in Avena. Washington, US Department of Agriculture. 101p. (Technical Bulletin, 1308).

Cruz CD (2006) Programa Genes: Biometria. Viçosa, Editora UFV. $382 \mathrm{p}$.

Cruz CD \& Carneiro PCS (2003) Modelos biométricos a aplicados ao melhoramento genético. Viçosa, Editora UFV. 585p.

Floss EL (1988) Aveia. In: Baier AC, Floss EL \& Aude MIS (Eds.) As lavouras de inverno. Rio de Janeiro, Globo. p.17-74.

Germeir CU (2008) Global strategy for the ex situ conservation of oats (Avena spp.). Queldinburg, Federal Centre for Breeding Research on Cultivated Plants (BAZ). 78p.

IBPGR (1985) Oat descriptors. Rome, International Board for Plant Genetics Resources. 21p.

Kuinchtner A \& Burial GA (2001) Clima do estado do Rio Grande do Sul segundo a classificação de Köppen e Thornthwaite. Disciplinarum Scientia. Série Ciências Exatas, 2:171-182.

Kurek AJ, Carvalho FIF de, Cruz P, Lorencetti C, Cargnin A \& Simioni D (2002) Variabilidade em genótipos fixos de aveia branca estimada através de caracteres morfológicos. Revista Brasileira de Agrociência, 8:13-17.

Leggett JM (1992) Classification and speciation in Avena. Agronomy, 33:29-52.

Luby JJ \& Stuthman DD (1983) Evaluation of Avena sativa L./ Avena fatua L. progenies for agronomic and grain quality characters. Crop Science, 23:1047-1052.

Matiello RR, Sereno MJCM, Barbosa Neto JF, Carvalho FIF, Pacheco MT, Pegoraro DG \& Taderka I (1999) Characterization for plant height and flowering date in the biological species oat. Pesquisa Agropecuária Brasileira, 34:1393-1398.

Mcginnis RC \& Lin CC (1966) A monosomic study of panicle shape in Avena sativa. Canadian Journal of Genetics and Cytology, 8:96-101.

Morikawa T (1989) Genetic analysis on dwarfness of wild oats, Avena fatua. Japanese Journal of Genetics, 64:363-371.

Singh D (1981) The relative importance of characters affecting genetic divergence. The Indian Journal of Genetic and Plant Breeding, 41:237-245.

Sneath PH \& Sokal RR (1973) Numerical taxonomy: The principles and practice of numerical classification. San Francisco, W H Freeman. 573p.

Sokal RR \& Rohlf FJ (1962) The comparison of dendrograms by objective methods. Taxon, 11:33-40.

Somersalo S, Mäkelä P, Rajala A, Nevo E \& Peltonen-Sainio P (1998) Morpho-physiological traits characterizing environmental adaptation of Avena barbata. Euphytica, 99:213-220. 
Sudré CP, Cruz CD, Rodrigues R, Riva EM, Amaral Júnior AT, Silva DJH \& Pereira TNS (2006) Variáveis multicategóricas na determinação da diversidade genética entre subamostras de pimenta e pimentão. Horticultura Brasileira, 24:88-93.

Swarbreck SM, Lindquist EA, Ackerly DD \& Andersen GL (2011) Analysis of leaf and root transcriptomes of soil-grown Avena barbata plants. Plant Cell Physiology, 52:317-332.

Tavares MJCMS, Zanettini MHB \& Carvalho FIF (1993) Origem e evolução do gênero Avena: Suas implicações no melhoramento genético. Pesquisa Agropecuária Brasileira, 28:499-507.
Vendramini JM, Neves LG, Barelli MAM, Elias JCF \& Luz PB da (2011) Otimização do uso dos descritores morfo-agronômicos de mandioca em análise multivariada. Revista Ciência Agronômica, 42:906-913.

Zadoks JC, Chang TT \& Konzac CF (1974) A decimal code for the growth stages of cereals. Weed Research, 14:415-421.

Zarco CR (1990) Las avenas del grupo barbata en la Península Ibérica y Baleares. Lagasclia, 16:243-268. 